\title{
Epidemiology, Clinical Characteristics, and Prognostic Factors of Atopic Children Hospitalised for Adenovirus Infection: A Single Institutional Study in Shenyang, China
}

Miao Li ( $\sim$ Impediatrician@126.com )

Shengjing Hospital of China Medical University https://orcid.org/0000-0002-2232-831X

Xiao-Hua Han

Shengjing Hospital of China Medical University

Li-Yun Liu

Shengjing Hospital of China Medical University

Hui-Sheng Yao

Shengjing Hospital of China Medical University

Li-Li Yi

Shengjing Hospital of China Medical University

\section{Research article}

Keywords: Adenoviral infection, Atopy, Children, small airway lesions

Posted Date: August 5th, 2020

DOI: https://doi.org/10.21203/rs.3.rs-51134/v1

License: (c) (i) This work is licensed under a Creative Commons Attribution 4.0 International License.

Read Full License 


\section{Abstract}

Background: Atopy may be associated with the severity of disease and poor prognosis after adenovirus (Adv) infection in children. Our aim was to observe the clinical characteristics and pulmonary radiological changes in atopic children with Adv pneumonia in China.

Methods: Children hospitalised for Adv pneumonia from June 2018 to Dec 2019 were analysed. All children were divided into three groups: atopic with Adv, non-atopic with Adv, and atopic without Adv infection. Each group was further divided into mild or severe infection groups according to disease severity. Standard treatment was initiated after admission and regular follow-up evaluations were conducted at 1 month after discharge. Baseline and clinical characteristics, and pulmonary radiological changes of atopic and non-atopic children were collected. Risk factors associated with small airway diseases in Adv pneumonia patients were analyzed.

Results: Compared with non-atopic children with Adv infection, the cases of eosinophilic granulocyte count were significantly higher in atopic children than non-atopic children $(P<0.05)$. Among children with mild and severe infection, the number of patients with wheezing and small airway disease as observed by high-resolution computed tomography (HRCT) was significantly higher in atopic children than non-atopic children $(P<0.05)$. Furthermore, coughing was more severe in atopic children than non-atopic children $(P<0.05)$. A family history of asthma (OR 2.1 [95\% Cl 1.8-3.0]), personal history of asthma (OR 2.7 [95\% $\mathrm{Cl} 2.1-3.1]$ ), atopy (OR 2.1 [95\% Cl 1.8-3.2]), severe infection (OR 1.9 [95\% $\mathrm{Cl} 1.0-2.7]$ ), and Adv infection (OR 1.4, [95\% Cl 0.9-2.0]) were independent factors associated with the development of small airway disease, both after admission and a month after discharge.

Conclusions: Atopic children with Adv infection experience more severe coughing during hospitalisation and are prone to wheezing and small airway disease on the HRCT. Family and personal history of asthma, atopy, severe infection, and Adv infection were independent factors associated with the development of small airway disease on the chest HRCT scan.

\section{Background}

Human adenovirus (HAdv) infection is a major cause of community-acquired pneumonia in infants and young children $(1,2)$. Adv pneumonia generally occurs in patients between 6 months and 5 years of age, and especially affects children $<2$ years of age. Nearly $5 \%$ of children infected with Adv develop pneumonia and nearly 1.3 million children die annually due to Adv infection $(3,4)$. The mortality rate of severe untreated pneumonia or disseminated disease caused by Adv may exceed $50 \%(5,6)$. Children with severe Adv pneumonia often require hospitalization due to more severe clinical manifestations and extrapulmonary complications. Some patients also develop chronic airway and lung diseases that may lead to death (7). Despite continuous developments in medical technology and standardized Adv treatment being increasingly administered, some children still have a poor prognosis; thus, Adv infection still requires further attention. After infection, up to $30 \%$ of children have long-term respiratory 
complications, such as post-infection bronchiolitis obliterans (10) and bronchiectasis (11), as well as an irreversible decline in lung function (12). Therefore, understanding the prognosis of adenovirus-infected children is the focus of the current research. We are particularly addressing the question of why do some children experience severe symptoms and why do they have a poor prognosis. In recent years, most clinical studies have focused on virus typing $(13,14,15)$, but few studies have assessed the risk factors associated with a poor prognosis. Previous regional studies in Singapore have shown that an Adv type 7 infection, a severe infection requiring invasive or non-invasive ventilation, and a family or personal history of asthma were risk factors for respiratory complications (16).

In children, atopy usually manifests as atopic dermatitis, allergic rhinitis, and allergic asthma; however, some children experience airway hyper responsiveness (17). Allergic inflammation may affect immunity; thus atopic children may be prone to recurrent respiratory tract infections (18) and some children may experience sequelae (16). Many atopic children with Adv infection experience wheezing and slower recovery, thus requiring long-term atomisation. This suggests that atopy may be related to the severity and poor prognosis of Adv infection. In our study we aimed to analyse the baseline and clinical characteristics, and pulmonary radiological changes in atopic and non-atopic children with adenovirus infection, to establish whether atopy is the one of the risk factors for small airway changes observed during high-resolution computed tomography (HRCT) after adenovirus infection. Early identification of risk factors is particularly important so that clinicians can implement intervention strategies earlier to improve the patient's prognosis.

\section{Methods}

\section{Study population}

A total of 200 children were included. 120 children hospitalized for Adv pneumonia from June 2018 to December 2019 from the Pediatric Respiratory Department of Shengjing Hospital were included and 80 atopic children without Adv infection were selected as the control. The inclusion criteria were pneumoniainfected children, 1 month to 14 years of age. Children with congenital pulmonary dysplasia, airway malformation, congenital immune deficiency disease, congenital heart disease, malnutrition, or congenital metabolic diseases were excluded. The need for patient consent was waived by the ethics committee.

\section{Study definitions}

Pneumonia was diagnosed based on the patient's symptoms (fever, cough, and/or rapid breathing) and clinical evidence of pneumonia (tachypnoea, chest recessions, and/ or adventitious sounds upon lung auscultation), with radiographic signs (infiltrates or consolidation). Severe HAdV pneumonia was defined when patients required either invasive or non-invasive respiratory support, pediatric intensive care unit care or illness resulting in death. Atopy was diagnosed by a specialist based on the patient's history of 
atopic dermatitis, asthma or allergic rhinitis, the specific allergen IgE quantitation test, and skin scratch experiment.

\section{Data collection}

The clinical medical records of children were retrospectively reviewed and analyzed for the following data: age; sex; duration of fever; duration of hospitalization; laboratory test results at the first admission (neutrophil count, eosinophil count, lymphocyte count, C-reactive protein (CRP) level); the presence of wheezing at admission, after discharge, and 1 month after discharge; the presence of severe cough (nocturnal cough or vomiting after cough); chest CT scan or X-ray (children with wheezing required an HRCT scan), and the presence of small airway lesions on the chest HRCT scan. Two specialists in chest radiography independently reviewed the scans. Baseline and clinical characteristics, as well as pulmonary radiological changes in atopic and non-atopic children were collected. Risk factors associated with post-adenovirus pneumonia with small airway diseases were analyzed.

In the atopic children, allergen specific IgE quantitation detection and skin scratch experiments were also performed within $24 \mathrm{~h}$ if they did not undergo a specific allergen IgE quantitation test within the last six months. And avoid exposure of children to allergens, if specific lgE levels were over 0.35KUA/L. (Allergenspecific IgE testing kit; Semel Technologies, Ltd., Shenyang, China).

\section{Specimen collection, virus identification}

Nasopharyngeal swabs for the Adv antigen (Respiratory Virus detection kit; Shanghai Xing Yao Medicine Technology Development Co., Ltd., Shanghai, China) and Adv DNA identification (Adv RNA detection kit; Shenzhen PuRuiKang Biological Technology, Co., Ltd., Shenzhen, China) were collected within $24 \mathrm{~h}$ after admission.

\section{Treatment modalities}

The diagnosis and treatment of Adv infection was performed according the State Administration of National Health Commission of the People's Republic of China and national guidelines published in 2019 (19). All children received standard treatment for pneumonia, which included supportive care when necessary, invasive or non-invasive ventilation, and antibiotics. Intravenous immunoglobulin was administered to children with persistent fever and intravenous pulse methylprednisolone was administered to children with severe disease i.e. rapidly increasing respiratory distress, at the discretion of the treating physician. Children with wheezing were treated with a bronchodilator to relax the airway. Children without a fever $>48 \mathrm{~h}$, no wheezing, relieved cough, and a $50 \%$ decrease in infiltrates or the consolidation area after admission were discharged from the hospital. A follow-up visit was scheduled 1 month after discharge for children who experienced wheezing or had an abnormal chest HRCT, to observe 
whether wheezing remained and to assess changes in the chest HRCT. If the chest CT scan results were reverted to normal before discharge, no re-examination was required.

\section{Statistical analysis}

Baseline, clinical characteristics, and pulmonary radiological changes in atopic and non-atopic children were collected. Risk factors associated with small airway diseases in Adv pneumonia patients were analyzed. The continuous variables are described as mean \pm standard deviation. A one-way analysis of variance (ANOVA) was used to assess the differences among the three groups, and Student-NewmanKeuls test or Least Significant Difference tests were used as the post hoc test. The Chi-square test was applied for the categorical variables, and multivariate analysis was used to for risk factors associated with small airway diseases in post-adenovirus pneumonia patients. Spearman's test was used to assess correlation. All statistical analyses were conducted using SPSS 20.0. Two-sided P values $<0.05$ were considered statistically significant.

\section{Results}

A total of 200 children were included; 120 children were hospitalized for Adv infection and 80 atopic children without Adv infection were selected as controls. Of the Adv patients, 42 patients were designated to the atopic group and 78 patients were designated to the non-atopic group. Based on the history of atopy, a total of 122 patients, both with and without Adv, were atopic and 78 patients were non-atopic. There were 80 cases of mild infection ( 30 atopic cases and 50 non-atopic cases) and 40 cases of severe infection (12 atopic cases and 28 non-atopic cases). The 80 atopic without Adv infection children were further divided into two groups according to the disease severity ( 40 with mild infection and 40 with severe infection) (Fig. 1).

\section{Baseline and laboratory characteristics of children were hospitalised with atopy and non-atopy}

Of the 200 children,there were 62 boys and 60 girls in the atopic group, and 45 boys and 33 girls in the non-atopic group. There was no difference in sex, age, neutrophil count, and lymphocyte count in blood routine test $(P>0.05)$ between the atopic and non-atopic group. However, eosinophil counts in atopic group were significantly higher than that in non-atopic group. $(P<0.05$; Table 1$)$. 
Table 1

Baseline and laboratory characteristics of children with atopy and non-atopy

\begin{tabular}{|lllll|}
\hline Group & Atopy $(\mathbf{n}=\mathbf{1 2 2})$ & Non-atopy $(\mathbf{n}=\mathbf{7 8})$ & $\mathrm{X}^{2} /$ t-test & $\boldsymbol{P}$ value \\
\hline Male & $62(50.8 \%)$ & $45(57.7 \%)$ & 0.133 & 0.716 \\
\hline Female & $60(49.2 \%)$ & $33(42.3 \%)$ & & \\
\hline age & $5.2 \pm 1.2$ & $5.5 \pm 0.6$ & 1.230 & 0.34 \\
\hline Neutrophil count & $(11.21 \pm 0.03) \times 10^{9} / \mathrm{L}$ & $(11.80 \pm 0.01) \times 10^{9} / \mathrm{L}$ & 1.280 & 1.050 \\
\hline Lymphocyte count & $(2.74 \pm 0.02) \times 10^{9} / \mathrm{L}$ & $(2.80 \pm 0.13) \times 10^{9} / \mathrm{L}$ & 1.460 & 0.120 \\
\hline eosinophil count & $(0.53 \pm 0.01) \times 10^{9} / \mathrm{L}$ & $(0.22 \pm 0.01) \times 10^{9} / \mathrm{L}$ & 1.829 & $0.020^{*}$ \\
\hline CRP & $(36.27 \pm 1.52) \mathrm{mg} / \mathrm{L}$ & $(38.36 \pm 2.69) \mathrm{mg} / \mathrm{L}$ & 1.140 & 0.180 \\
\hline$* P<0.05$, compare with non-atopic group statistically significant. CRP: C-reactive protein; \\
\hline
\end{tabular}

Differences in clinical characteristics of atopic and non-atopic children with mild adenovirus infection

Considering that children with different levels of severity after infection show different results on the chest HRCT, we compared clinical features between children with mild and severe pneumonia, respectively. The number of children in the atopic group (with Adv or without Adv infection) with mild pneumonia, severe cough, wheezing, and chest HRCT indicating small airway lesions at admission and 1 month after discharge were significantly higher than those in the non-atopic group $(P<0.05)$. There was no significant difference in hospitalization duration, duration of fever, among the three groups $(P>0.05$; Table 2). 
Table 2

Clinical and pulmonary radiological changes in mild infection children with or without atopy

\begin{tabular}{|c|c|c|c|}
\hline Group & $\begin{array}{l}\text { Atopic with } \\
\operatorname{Adv}(n=30)\end{array}$ & $\begin{array}{l}\text { Non-atopic with } \\
\operatorname{Adv}(n=50)\end{array}$ & $\begin{array}{l}\text { Atopic without } \\
\text { Adv }(n=40)\end{array}$ \\
\hline \multicolumn{4}{|l|}{ Clinic characteristics } \\
\hline Duration of fever(day) & $5.3 \pm 1.1$ & $5.5 \pm 0.8$ & $5 \pm 1.2$ \\
\hline Duration of hospitalization(day) & $8.2 \pm 1.5$ & $8.1 \pm 0.6$ & $7 \pm 1.0$ \\
\hline Cases of wheezing in hospital(\%) & $11(9.17 \%)^{\mathrm{ab}}$ & $5(4.17 \%)$ & $4(3.33 \%)^{\mathrm{a}}$ \\
\hline Cases of wheezing after discharge(\%) & $5(4.17 \%)^{a b}$ & $2(1.67 \%)$ & $3(2.5 \%)^{a}$ \\
\hline $\begin{array}{l}\text { Cases of severe cough } \\
\text { during hospitalization }\end{array}$ & $10(8.33 \%)^{a b}$ & $7(5.83 \%)$ & $8(6.67 \%)^{a}$ \\
\hline \multicolumn{4}{|l|}{ pulmonary radiological changes } \\
\hline $\begin{array}{l}\text { Cases have small airway lesions(on } \\
\text { admission) }\end{array}$ & $6(5 \%)^{a b}$ & $3(2.5 \%)$ & $4(3.33 \%)^{a}$ \\
\hline $\begin{array}{l}\text { Cases have small airway lesions(a } \\
\text { month after discharge) }\end{array}$ & $4(3.33 \%)^{\mathrm{ab}}$ & $2(1.67 \%)$ & $1(0.83)^{a}$ \\
\hline
\end{tabular}

\section{Differences in clinical features and radiological changes between atopic and non-atopic children with severe Adv pneumonia}

The cases of wheezing during hospitalization and after discharge in the atopic group (with Adv or without Adv infection) with severe pneumonia was significantly higher than that in the non-atopic group $(P<$ 0.05). A total of nine atopic children with small airway lesions were admitted to the hospital (5 cases with excessive permeability, three cases with mosaic sign, and one case with bronchial wall thickening). There were significant differences in the number of patients who had small airway lesions during hospitalization and after discharge among the three groups $(P<0.05)$. The number of patients with small airway diseases during hospitalization and after discharge in the atopic group (with Adv or without Adv infection) with severe pneumonia was significantly higher than those in the non-atopic group $(P<0.05)$. There was no statistical difference in blood oxygen saturation, CRP levels, hospitalization time, and duration of fever among the three groups $(P>0.05$; Table 3$)$. 
Table 3

Clinical and pulmonary radiological changes in severe infection children with or without atopy

Group
Atopic with

$\operatorname{Adv}(n=12)$
Non-atopic with

Adv $(n=18)$
Atopic without

Adv $(n=40)$

\section{Clinical features}

Degree of blood oxygen saturation

$(78.33 \pm 2.35) \%$

$(80.24 \pm 3.25) \%$

$(79 \pm 2.16) \%$

Cases of dyspnea(\%)

$8(10 \%)^{a b}$

$21(26.25 \%)$

$15(18.75)^{\mathrm{a}}$

Duration of fever(day)

$7.1 \pm 1.1$

$7.3 \pm 0.8$

$7 \pm 0.9$

Duration of hospitalization(day)

$9.2 \pm 1.5$

$9.3 \pm 0.6$

$9 \pm 1.3$

Cases of wheezing in hospital(\%)

$8(10 \%)^{a b}$

$4(5 \%)$

$6(7.5 \%)^{\mathrm{a}}$

Cases of wheezing after discharge(\%)

$4(5 \%)^{a b}$

$2(2.5 \%)$

$4(5)^{\mathrm{a}}$

Cases of extra-pulmonary

complications(\%)

$6(7.5 \%)^{a b}$

15(18.75\%)

$20(25 \%)^{\mathrm{a}}$

\section{pulmonary radiological changes}

Cases have small airway lesions(on admission)

$9(11.25 \%)^{a b} \quad 5(6.25 \%)$

$7(8.75 \%)^{\mathrm{a}}$

Cases have inflammation more than a lobe

$11(13.75 \%)^{a b}$

$15(25 \%)$

$16(20 \%)^{a}$

Cases have small airway lesions(a month after discharge)

$4(5 \%)^{a b}$

$1(1.25 \%)$

$3(3.75 \%)^{\mathrm{a}}$

${ }^{a} P<0.05$, compare with non-atopic with Adv group statistically significant. ${ }^{b} P<0.05$, compare with atopic without Adv group statistically significant.

\section{Risk factors associated with post-Adv pneumonia with small airway diseases}

Because small airway disease is the most common complication of post-Adv infection, we compared the baseline characteristics and symptoms of the children with pneumonia with and without small airway diseases to identify the risk factors of small airway disease. According to the imaging findings, 200 children were divided into two groups according to the presence or absence of small airway lesions. We found that in the small airway diseases group, the number of patients with atopy, severe infection, and a family or personal history of asthma were statistically higher compared with patients in the non-small airway disease group ( $P<0.05$; Table 4$)$. We also performed a multivariate analysis to identify risk factors associated with small airway diseases in post-Adv pneumonia patients. We found that family history of asthma (OR 2.1 [95\% Cl 1.8-3.0]), personal history of asthma (OR 2.7 [95\% $\mathrm{Cl} 2.1-3.1]$ ), atopy (OR 2.1 
[95\% Cl 1.8-3.2]), severe infection (OR 1.9 [95\% Cl 1.0-2.7]), and Adv infection (OR 1.4, [95\% Cl 0.9-2.0]) were independent factors associated with the development of small airway disease on the chest HRCT scan (Table 5). The risks of small airway disease in children who had a family history of asthma, personal history of asthma, and severe infection, atopy, and Adv infection were 2.1, 2.7, 1.9, 2.1, and 1.4 times higher than children without these characteristics, respectively. 
Table 4

Baseline characteristics, symptoms of the 200 children with pneumonia with and without small airway diseases

\begin{tabular}{|c|c|c|c|c|c|}
\hline Characteristics & $\begin{array}{l}\text { Total } \\
\left(\begin{array}{l}n=200) n \\
\%)\end{array}\right.\end{array}$ & $\begin{array}{l}\text { With small } \\
\text { airway diseases } \\
(n=34) n(\%)\end{array}$ & $\begin{array}{l}\text { Without small } \\
\text { airway diseases } \\
(n=166) n(\%)\end{array}$ & $\begin{array}{l}X^{2} / t- \\
\text { test }\end{array}$ & $\begin{array}{l}P \\
\text { value }\end{array}$ \\
\hline Atopy & & & & 6.556 & $0.01^{*}$ \\
\hline yes & $122(61 \%)$ & $26(76.5 \%)$ & $96(59.6 \%)$ & & \\
\hline No & $78(39 \%)$ & $8(23.5 \%)$ & $69(41.4 \%)$ & & \\
\hline Severe infection & & & & 13.975 & $0.01^{*}$ \\
\hline yes & $80(40 \%)$ & $21(61.8 \%)$ & $59(35.5 \%)$ & & \\
\hline No & $120(60 \%)$ & $13(38.2 \%)$ & $107(64.5 \%)$ & & \\
\hline Fever & & & & 0.02 & 0.887 \\
\hline yes & $110(55 \%)$ & $16(47.1 \%)$ & $80(48.2 \%)$ & & \\
\hline No & $90(45 \%)$ & $18(52.9 \%)$ & $86(51.8 \%)$ & & \\
\hline $\begin{array}{l}\text { Duration of } \\
\text { hospitalization }\end{array}$ & & $8.2 \pm 1.1$ & $8.3 \pm 0.7$ & 0.984 & 0.06 \\
\hline $\begin{array}{l}\text { Family history of } \\
\text { asthma }\end{array}$ & & & & 35.498 & $0.001 *$ \\
\hline yes & $50(25 \%)$ & $20(58.8 \%)$ & $30(18.1 \%)$ & & \\
\hline No & $150(75 \%)$ & $14(41.2 \%)$ & $136(81.9 \%)$ & & \\
\hline $\begin{array}{l}\text { Previous chest } \\
\text { infection }\end{array}$ & & & & 0.041 & 0.84 \\
\hline yes & $55(27.5 \%)$ & $9(26.5 \%)$ & $46(27.7 \%)$ & & \\
\hline No & $145(72.5 \%)$ & $25(73.5 \%)$ & $120(72.3 \%)$ & & \\
\hline Passive smoking & & & & 0.471 & 0.493 \\
\hline yes & $54(27 \%)$ & $8(23.5 \%)$ & $46(27.7 \%)$ & & \\
\hline No & $146(73 \%)$ & $26(76.5 \%)$ & $120(72.3 \%)$ & & \\
\hline $\begin{array}{l}\text { Personal history } \\
\text { of } \\
\text { asthma/wheeze }\end{array}$ & & & & 31.165 & $0.001 *$ \\
\hline
\end{tabular}

$\star P<0.05$, compare with the group without small airway diseases statistically significant. 


\begin{tabular}{|llllll|}
\hline Characteristics & $\begin{array}{l}\text { Total } \\
(\mathbf{n = 2 0 0}) \mathbf{n}\end{array}$ & $\begin{array}{l}\text { With small } \\
\text { airway diseases } \\
(\mathbf{n}=\mathbf{3 4}) \mathbf{n}(\%)\end{array}$ & $\begin{array}{l}\text { Without small } \\
\text { airway diseases } \\
(\mathbf{n = 1 6 6}) \mathbf{n}(\%)\end{array}$ & $\begin{array}{c}\mathrm{X}^{2} / \mathrm{t}- \\
\text { test }\end{array}$ & $\begin{array}{l}\boldsymbol{P} \\
\text { value }\end{array}$ \\
\hline yes & $81(67.5 \%)$ & $25(73.5 \%)$ & $56(33.7 \%)$ & \\
\hline No & $119(23.5 \%)$ & $9(26.5 \%)$ & $110(66.3 \%)$ & 5.937 & $\mathbf{0 . 0 1 5 ^ { * }}$ \\
\hline Adv infection & & & & & \\
\hline yes & $120(60 \%)$ & $23(67.6 \%)$ & $97(58.4 \%)$ & \\
\hline No & $80(40 \%)$ & $11(23.4 \%)$ & $69(41.6 \%)$ & \\
\hline$* P<0.05$, compare with the group without small airway diseases statistically significant. & \\
\hline
\end{tabular}

Table 5

Multivariate analysis of risk factors associated with post-adenovirus pneumonia with small airway diseases

\begin{tabular}{|c|c|c|c|c|c|}
\hline Characteristics & $\begin{array}{l}\text { Total }(n= \\
200) n \\
(\%)\end{array}$ & $\begin{array}{l}\text { With small airway } \\
\text { disease }(n=34) n \\
(\%)\end{array}$ & $\begin{array}{l}\text { Without small airway } \\
\text { diseases }(n=166) n \\
(\%)\end{array}$ & $\begin{array}{l}P \\
\text { value }\end{array}$ & $\begin{array}{l}\text { Odds ratio } \\
95 \% \\
\text { (Confidence } \\
\text { interval) }\end{array}$ \\
\hline Atopy & $122(61 \%)$ & $26(76.5 \%)$ & $96(59.6 \%)$ & $0.021^{*}$ & $\begin{array}{l}2.1(1.8- \\
3.2)\end{array}$ \\
\hline Severe infection & $80(40 \%)$ & $21(61.8 \%)$ & $59(35.5 \%)$ & $0.020 *$ & $1.9(1.0-2.7)$ \\
\hline $\begin{array}{l}\text { Family history } \\
\text { of asthma }\end{array}$ & $50(25 \%)$ & $20(58.8 \%)$ & $30(18.1 \%)$ & $0.019 *$ & $2.4(1.8-3.0)$ \\
\hline $\begin{array}{l}\text { Personal history } \\
\text { of } \\
\text { asthma/wheeze }\end{array}$ & $81(67.5 \%)$ & $25(73.5 \%)$ & $56(33.7 \%)$ & $0.018^{*}$ & $\begin{array}{l}2.7(2.1- \\
3.1)\end{array}$ \\
\hline Adv infection & $120(60 \%)$ & $23(67.6 \%)$ & $97(58.4 \%)$ & $0.023^{*}$ & $\begin{array}{l}1.4(0.9- \\
2.2)\end{array}$ \\
\hline
\end{tabular}

\section{Discussion}

Atopic children are a special population and atopy is often accompanied by airway hyperresponsiveness. In our study, we compared the clinical characteristics of atopic children with Adv-associated pneumonia to non-atopic children. We found that there was no difference in the duration of fever between the two groups. In atopic children (with Adv or without Adv infection) with pneumonia, the number of cases with severe cough and wheezing were significantly higher compared with those without atopy, and the number of patients with wheezing during hospitalization was significantly different. Therefore, we concluded that, after Adv infection, atopic children are more prone to severe cough and wheezing than non-atopic 
children. The reason for wheezing in atopic children with Adv pneumonia may be related to the exposure of the damaged airway epithelium neurons and increased airway sensitivity (20). Studies have shown that leukotriene E4 is strongly associated with episodes of acute wheezing in preschool children, and that higher levels of leukotriene E4 are present in the airways of atopic children than in the airways of nonatopic children (21); therefore, atopic children are more prone to wheezing. In contrast, it may also be related to the characteristics of Adv infection. Firstly, damage to the airway mucosa after Adv infection and the release of inflammatory mediators can cause bronchial and bronchioles mucosal edema, congestion, necrosis and shedding, necrotic obstruction of the lumen, and bronchial wall edema and thickening, resulting in vasospasm and muscle contraction. Because airway epithelial cells are damaged, its defence capacity is reduced, resulting in allergens invading the airway more easily (14), indirectly promoting airway inflammation, and further narrowing the airway lumen due to wheezing. On the other hand, toll-like receptors (TLR) and intracellular virus sensors such as protein-catalysed enzymes (protein kinase double-stranded RNA, PKR) in airway epithelial cells (15) induce MUC5AC production, leading to airway epithelial mucus hypersecretion, and blockage of the lumen. After infection, the HAdv can interact with host cells and extensively participate in the functions of host cell proliferation, apoptosis, autophagy, and so on (20). Studies have shown that when HAdv infects respiratory epithelial cells, host cells develop adaptive autophagy, which enables immune evasion (21), leading to autophagy dysregulation in host cells. Adv can induce the activation of $\mathrm{CD}^{+} \mathrm{T}$ cells through the autophagy pathway, leading to microenvironmental changes in the lung tissue (22). Activated $C D 8^{+} T$ cells lead to death of airway structural cells, repeated damage, and repair of the airway tissue, by releasing cytotoxic particles such as perforin and granzyme, and inflammatory mediators such as IFN- - , IL-10, and TNF- $a$, and inducing FAS/FASL expression to promote apoptosis. In the airways of atopic children, damaged neurons in the airway epithelia are exposed, increasing the airway sensitivity (23), and leading to more serious epithelial injury, thus making patients more susceptible to wheezing.

The changes caused by Adv pneumonia on the chest CT include lung consolidation, patchy shadows, flocculent shadows, cluster shadows, air bronchograms, and lymph node enlargement. Its effects on the small airways include uneven inflation, mosaic sign, bronchial thickening, and bronchiectasis (22). In the current study, we compared atopic and non-atopic children with Adv pneumonia and found that the percentage of atopic children with small airway lesions was greater than that of non-atopic children. We also compared the baseline characteristics and symptoms of children with pneumonia with and without small airway diseases. We found that in the small airway disease group the number of patients with atopy, severe infection, and family or personal history of asthma were significantly higher than those without small airway diseases. Family history of asthma, personal history of asthma, atopic, severe infection, and Adv infection were independent factors associated with the development of small airway disease on the chest HRCT scan.

Uneven inflation of the lungs is always found on the chest CT of atopic children, and children often experience coughing or wheezing which requires treatment after discharge. The changes in the lung parenchyma, such as lung consolidation, usually recover slowly after discharge and most small airway

Page $12 / 18$ 
lesions require atomisation to recover; however, we observed that, even after 1 month, some atopic children had small airway lesions on the chest CT. Some children were still intolerant to sports activities, had post-activity wheezing, and progressed to obliterative bronchitis.

The small airway refers to the airway with an inner diameter $\leq 2 \mathrm{~mm}$, and is one of the smallest visible areas of the lungs. Most of the airways are referred to as bronchioles, belonging to the 12th $\sim 23 \mathrm{rd}$ branch of the airway (23). There are direct and indirect manifestations of small airway diseases on the HRCT. The direct signs are caused by thickening of the bronchial wall or bronchiectasis, including central lobular nodules, tree bud signs, and bronchiectasis (25). Indirect signs are caused by obstruction of bronchioles, and include mosaic sign and gas trapping (25). In recent years, with advancements in imaging and medical instruments, the rate of small airway lesion detection has increased, especially with the widespread use of HRCT. HRCT imaging of small airway lesions can detect the following: thickening of the bronchiole wall; tree bud sign; mosaic characteristics; and air retention. The mechanism for development of small airway lesions in atopic children may be eosinophilia and an abundance of CD $4^{+} T$ lymphocytes in the small airways compared to larger airways, which results in small airway inflammation (26). Small airway inflammation, airway remodelling, and matrix deposition eventually leads to increased airway resistance, similar to the pathophysiologic changes that occur in the small airways of asthmatic patients (27). In contrast, small airway lesions are also associated with persistent latent infection of the Adv E1A genes. The adenovirus genome is linear double-stranded DNA, containing five early transcription units, namely E1A, E1B, E2, E3, and E4. The viral genome translocates to the host nucleus, and its transcription and expression initiates and facilitates viral replication. E1A is the earliest transcribed gene (28). Studies have demonstrated that the adenoviral E1A DNA and proteins persist in the lung tissue after viral replication stops in the acute infection phase and enables the long-term expression of proteins without the need for replication of the entire virus. The main target cells are bronchial epithelial cells, alveolar epithelial cells, and submucosal cells (29). Studies have shown that enhanced expression of E1A genes can activate the mitogen-activated protein kinase (MAPK) signalling pathway, allowing HAdv to proliferate continuously in respiratory epithelial cells (26). Persistent latent infection of the lung tissue by E1A genes may lead to airway remodelling (30).

There are many limitations to our study. We only considered the influence of atopy on the clinical symptoms of children, and other confounding factors that may also affect the prognosis of children, such as co-infection with respiratory syncytial virus (30), mycoplasma, influenza (31), or influenza mixed infections were not considered. In some patients with wheezing, the use of glucocorticoids to suppress immune responses may have also affected the prognosis of pneumonia, which was not considered in this study. The difference in the timing of treatment for some severe pneumonia patients may also affect their prognosis, which was not considered in this study (32) and warrants further investigation. In addition, we only analysed patients with small airway disease 1 month after discharge, and more research conducted over a longer period of time is warranted.

\section{Conclusion}


Atopic children with Adv pneumonia may experience severe coughing and wheezing in mild and severe cases. Atopic children are more susceptible to developing small airway lesions, recurrent wheezing after discharge, and slower recovery of small airway lesions as observed by chest imaging. A family history of asthma, personal history of asthma, atopy, severe infection, and Adv infection are independent factors associated with the development of small airway disease on the chest HRCT scan.

\section{Abbreviations}

Adv: Adenovirus; HRCT: High-resolution computer tomography; CRP: C-reactive protein; CC: $C$ iu $\mathrm{CH}$; MAPK: Mitogen-activated protein kinase; TLR: Toll-like receptors

\section{Declarations}

\section{Ethics approval and consent to participate}

The study was approved by the Research Ethics Committee of China Medical University (No: 2020PS005K; Shenyang, China). Written informed parental consent was obtained after admission.

\section{Consent for publication}

This study was retrospective and ethic committee approved anonymous publication of data.

\section{Funding}

Not applicable

\section{Availability of data and materials}

The datasets used and/or analysed during the current study are available from the corresponding author on reasonable request.

\section{Competing interests}

The authors declare that they have no competing interests

\section{Author Contributions}

ML conceptualised and designed the study, drafted the initial manuscript, and reviewed and revised the manuscript. LYL and HSY designed the data collection instruments, coordinated, and supervised data 
collection, and reviewed and revised the manuscript. XHH performed the initial analyses, and critically reviewed the manuscript for important intellectual content. All authors approved the final manuscript as submitted and agree to be accountable for all aspects of the work.

\section{Acknowledgements}

The authors are extremely grateful for the enthusiasm and time provided by the parents and participants in this study.

\section{References}

1. Nascimento-Carvalho. CM.Etiology of childhood community acquired pneumonia and its implications for vaccination. Braz J Infect Dis. 2001;5(2):87-97. DOI:10.1590/S141386702001000200007.

2. Kim SJ, Kim K, Park SB, Hong DJ, Jhun BW. Outcomes of early administration of cidofovir in nonimmunocompromised patients with severe adenovirus pneumonia. PLoS One.2015 Apr 15;10(4):e0122642. DOI:10.1371/journal.pone.0122642.

3. Bhutta ZA, Das JK, Walker N, Rizvi A, Campbell H, Rudan I,et al. Interventions to address deaths from childhood pneumonia and diarrhoea equitably: What works and at what cost? Lancet. $2013 \mathrm{Apr}$ 20;381(9875):1417-1429. DOI :10.1016/S0140-6736(13)60648-0.

4. Agweyu A, Kibore M, Digolo L, Kosgei C, Maina V, Mugane S, et al. Prevalence and correlates of treatment failure among Kenyan children hospitalised with severe community-acquired pneumonia: a prospective study of the clinical effectiveness of WHO pneumonia case management guidelines. Trop Med Int Health. 2014;19(11):1310-20. DOl:10.1111/tmi.12368.

5. Lynch JP 3rd, Kajon AE. Adenovirus: epidemiology, global spread of novel serotypes, and advances in treatment and prevention. Semin Respir Crit Care Med. 2016;37(4):586-602. DOI:10.1055/s-00361584923.

6. Sandkovsky U, Vargas L, Florescu DF. Adenovirus: current epidemiology and emerging approaches to prevention and treatment. Curr Infect Dis Rep. 2014Aug;16(8):416. DOI:10.1007/s11908-014-0416-y.

7. Lin MR, Yang SL, Gong YN, Kuo CC, Chiu CH, Chen CJ, Hsieh YC, Kuo CY, Fang CW, Tsao KC, Huang YC. Clinical and molecular features of adenovirus type 2, 3, and 7 infections in children in an outbreak in Taiwan, 2011. Clin Microbiol Infect. 2017 Feb;23(2):110-6.

8. Rajkumar V, Chiang CS, Low JM, Cui L, Lin RT, Tee NW, et al. Risk factors for severe adenovirus infection in children during an outbreak in Singapore. Ann Acad Med Singapore. 2015Feb;44(2):509.

9. Ng OT, Thoon KC, Chua HY, Tan NW, Chong CY, Tee NW, et al. Severe pediatric adenovirus 7 disease in Singapore linked to recent outbreaks across Asia. Emerg Infect Dis. 2015Jul;21(7):1192-6. DOI:10.3201/eid2107.141443. 
10. de Blic J, Deschildre A, Chinet T. Post-infectious bronchiolitis obliterans. Rev Mal Respir. 2013Feb;30(2):152-60. DOI:10.1002/ppul.24221.

11. Murtagh P, Giubergia V, Viale D, Bauer G, Pena HG. Lower respiratory infections by adenovirus in children. Clinical features and risk factors for bronchiolitis obliterans and mortality. Pediatr Pulmonol. 2009 May;44(5):450-6. DOI:10.1002/ppul.20984.

12. Castro-Rodriguez JA, Daszenies C, Garcia M, Meyer R, Gonzales R. Adenovirus pneumonia in infants and factors for developing bronchiolitis obliterans: a 5-year follow-up. Pediatr Pulmonol. 20060ct;41(10):947-53. DOI:10.1002/ppul.20472.

13. Charlton CL, Babady E, Ginocchio CC, Hatchette TF, Jerris RC, Li Y, et al. Practical Guidance for Clinical Microbiology Laboratories: Viruses Causing Acute Respiratory Tract Infections. Clin Microbiol Rev. 2019Jan; 32(1): e00042-18. DOI: 10.1128/CMR.00042-18.

14. Wang B, Li J, Wu S, Chen Y, Zhang Z, Zhai Y, et al. Seroepidemiological investigation of HAdV-4 infection among healthy adults in China and in Sierra Leone, West Africa. Emerg Microbes Infect. 2018;7:200. DOI:10.1038/s41426-018-0206-y.

15. Fu Y, Tang Z, Ye Z, Mo S, Tian X, Ni K, et al. Human adenovirus type 7 infection causes a more severe disease than type 3. BMC Infect Dis. 2019;19:36. DOI:10.1186/s12879-018-3651-2.

16. Li L, Woo YY, de Bruyne JA, Nathan AM, Kee SY, Chan YF, et al. Epidemiology, clinical presentation and respiratory sequelae of adenovirus pneumonia in children in Kuala Lumpur, Malaysia. PLoS One. 2018;13(10):e0205795. DOI:10.1371/journal.pone.0205795.

17. Shim E, Lee E, Yang SI, Jung YH, Park GM, Kim HY, Seo JH, Yu J. The Association of Lung Function, Bronchial Hyperresponsiveness, and Exhaled Nitric Oxide Differs Between Atopic and Non-atopic Asthma in Children. Allergy Asthma Immunol Res. 2015 Jul;7(4):339-45. doi: 10.4168/aair.2015.7.4.339.

18. Woicka-Kolejwa K, Zaczeniuk M, Majak P, Pawłowska-Iwanicka K, Kopka M, Stelmach W, et al. Food allergy is associated with recurrent respiratory tract infections during childhood. Postepy Dermatol Alergol. 2016;33(2):109-13. DOI:10.5114/ada.2016.59151.

19. Lynch JP 3rd, Kajon AE. Adenovirus. Epidemiology, Global Spread of Novel Serotypes, and Advances in Treatment and Prevention. Semin Respir Crit Care Med. 2016Aug;37(4):586-602. DOI:10.1055/s0036-1584923.

20. Wang Z, Sun J, Liu Y, Wang Y. Impact of atopy on the severity and extrapulmonary manifestations of childhood Mycoplasma pneumoniae pneumonia. J Clin Lab Anal. 2019Jun;33(5):e22887. DOI:10.1002/jcla.22887.

21. Marmarinos A, Saxoni-Papageorgiou P, Cassimos D, Manoussakis E, Tsentidis C, Doxara A, et al. Urinary leukotriene E4 levels in atopic and non-atopic preschool children with recurrent episodic (viral) wheezing: a potential marker? J Asthma. 2015;52(6):554-9.

DOI:10.3109/02770903.2014.990092.

22. Li-hong Yao C, Wang Tian-li, Wei H, Wang Fen-lian, Ma. Li-shu Zheng. Human adenovirus among hospitalized children with respiratory tract infections in Beijing, China, 2017-2018. Virol J. 
2019;16:78. DOI:10.1186/s12985-019-1185-x.

23. Bake B, Larsson P, Ljungkvist G, Ljungström E, Olin AC. Exhaled particles and small airways. Respir Res. 2019;20:8. DOI:10.1186/s12931-019-0970-9.

24. Franquet T, Müller NL. Diserdem of the small airways: High-resolution computed tomographic feature. Semin Respir Crit Care Med. 2003;24(4):437-43. DOI:10.1055/s-2003-42378.

25. Takahashi M, Murata K, Takazakura R, Nakahara T, Shimizu K, Minese M. et a1. Bronchiolar disease: spectrum and radiological findings. Eur J Radiol. 2000Jul;35(1):15-29. DOI:10.1016/S0720048X(99)00155-2.

26. Balzar S, Wenzel SE, Chu HW. Transbronchial biopsy as a tool to evaluate small airways in asthma. Eur Respir J. 2002;20:254-9. DOI:10.1183/09031936.02.00261102.

27. Small airways disease and severe asthma.Tara F, Carr. Roula Altisheh, Myron Zitt. World Allergy Organ J. 2017; 10(1): 20. DOl:10.1186/s40413-017-0153-4.

28. Kirsten M, Spann E, Baturcam J, Schagen C, Jones, Claire P, Straub F, Maxine Preston,et al. Viral and host factors determine innate immune responses in airway epithelial cells from children with wheeze and atopy. Thorax. 20140ct; 69(10): 918-925. DOI:10.1136/thoraxjnl-2013-204908.

29. Yuksel $H$, Ahmet Turkeli. Airway epithelial barrier dysfunction in the pathogenesis and prognosis of respiratory tract diseases in childhood and adulthood. Tissue Barriers. 2017;5(4):e1367458. DOI:10.1080/21688370.2017.1367458.

30. Lee HJ, Seo YE, Han SB, Jeong DC. Jin Han Kang. Clinical Impact of Mixed Respiratory Viral Infection in Children with Adenoviral Infection. Infect Chemother. 2016Dec; 48(4): 309-316. DOI:10.3947/ic.2016.48.4.309.

31. Qian SH, Wang XH, Zhang L. Association between wheezing and Mycoplasma pneumoniae infection in infants and young children. Zhongguo Dang Dai Er Ke Za Zhi. 2016Nov; 18(11): 1090-1093. DOI:10.7499/j.issn.1008-8830.2016.11.007.

32. Kim SJ, Kim K, Park SB. Duck Jin Hong, Byung Woo Jhun. Outcomes of Early Administration of Cidofovir in Non-Immunocompromised Patients with Severe Adenovirus Pneumonia. PLoS One. 2015;10(4):e0122642. DOI:10.1371/journal.pone.0122642.

\section{Figures}




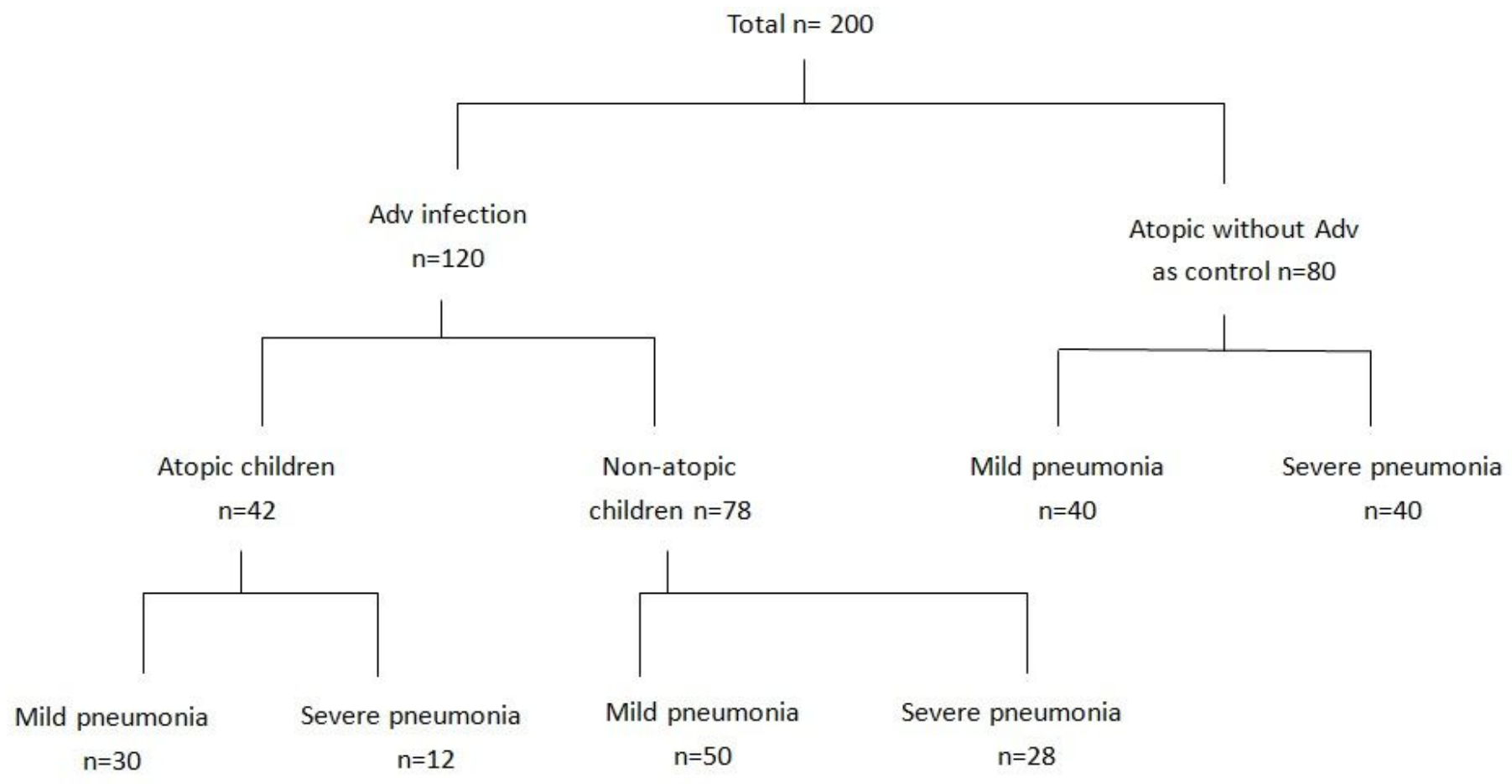

\section{Figure 1}

Screening of patient process maps. 120 children were studied. Based on the history of atopy, 42 patients were designated as the atopic group and 78 patients were designated as the non- atopic group. There were 23 boys and 19 girls in the atopic group, and 40 boys and 38 girls in the non- atopic group. 